\title{
Farmers in Degraded Forest in Thailand: Their Behavior and Socio-economic Conditions
}

\author{
Adisorn Noochdumrong ${ }^{* 1}$, Teunchai Noochdumrong*2 and Masahiro Amano*3
}

\begin{abstract}
Farmers' behavior and their socio-economic conditions were studied focusing on the agricultural land use patterns and production, as well as their basic needs. An interviewing survey of farmers living in some selected forest village projects was conducted using participatory rural appraisal tools and techniques. Findings showed that field crops was found to be the major agricultural land use in all sizes of landholding, especially in the North and Northeast. On the other hand, most of the farmers were more likely to grow field crops at first thought, regardless of the size of landholding. Unlikely, paddy rice (followed by field crops) was the major agricultural land use in the Central region, whereas rubber plantation was the major one in the South. The difference in agricultural land use by regions can be attributed to the geographical, socio-economic, and environmental characteristics of each region.

The species grown in degraded forests by the farmers were not much different between the North and the Northeast regions, except more fruit trees were planted in the North. Apart from corn and cassava, cotton and sugarcane were found to be the main cash crops in the Central region, and some fast growing tree species like Eucalyptus sp. could be generally planted in many areas. In the South, rambutan, coconut and durian were the most popular fruit trees of the region usually grown in areas of small landholding sizes. Regarding the basic needs of farmers, the most wanted ones were income; followed by land and water respectively. However, the three important basic needs mentioned here were together at all times when farmers' need was assessed.
\end{abstract}

Keywords: degraded forest, land use, land holding, agricultural production, farmers' need assessment

\section{INTRODUCTION}

Problem of deforestation in Thailand has been recognized and considered to be one of the most important and urgent government agendas. In the 1960 's, forest destruction was high, and rapidly increased to over 0.5 million ha. per year in the middle of the 1970 's. Since the 1980 's, the rate progressively decreased but is still unacceptably high at about

\footnotetext{
${ }^{* 1}$ National Park, Wildlife and Plant Conservation Department.

Address: 61 Paholyothin Rd., Chatujak, Bangkok 10900 THAILAND

${ }^{* 2}$ Royal Forest Department. Address: 61 Paholyothin Rd., Chatujak, Bangkok 10900 THAILAND

${ }^{* 3}$ School of Human Sciences, Waseda University Address: 2-579-15, Mikajima, Tokorozawa, Saitama, 359-1192, Japan.
}

180,000ha. per year. The average clearance since the first survey in 1961 until the latest in 1998 was approximately $420,000$ ha per year (RFD, $1986 ; 1989 ; 1995 ; 1999)$. The forest land areas decreased dramatically from $53.3 \%$ of the total land area in 1961 to $30.52 \%$ in $1982,26.64 \%$ in 1991 and recently to $25.28 \%$ in 1998 (RFD, 1999).

There are several recent empirical studies that attempt to identify and explain the role of factors causing deforestation on a global and national scale (cf. ALLEN and BARNES, 1985; Grainger, 1986; Palo et al., 1987; Panayotou and Sungsuwan, 1989; ReIs and Margulis, 1990; BILSBORROW and GEORES, 1994; SOUTHGATE, 1994). However, their results were conflicting and, therefore, inconclusive. For example, AlLEN and BARNES (1985), Grainger (1986), Panayoutou and Sungsuwan (1989), found that the population increase has a significant positive effect on the annual change in forested areas, while WESTOBY (1978) emphasized, that taken in isolation, there was no correlation between population variables and deforestation. Despite the fact that government policies prohibiting forest encroachment were later issued, Thai farmers continued the practice of migrating to clear new land when the agricultural 
area in their home communities was exhausted (GREPERUD, 1996). The abundance and wide distribution of forest lands ensured low production costs. It is estimated that there have been more than one million families living and cultivating in degraded forests.

One of the primary purposes of the government is to manage the conflict between national policy on land use and forests on one hand, and the needs of the people for land and forest products on the other. This study is aimed to explore farmers' activities, their socio-economic conditions and needs in relation to land use changes and forest encroachment. The study consists of two main parts - the first part focuses on the agricultural land use patterns and production, and the second part deals with basic needs assessment and the relationship between landholding, income, and needs.

\section{MATERIALS AND METHODS}

The collection of data on socio-economic conditions focusing on land use patterns, landholding size, agricultural production including need assessment was done by interviewing farmers living in 30 forest village projects representing all regions of the country (Fig. 1).

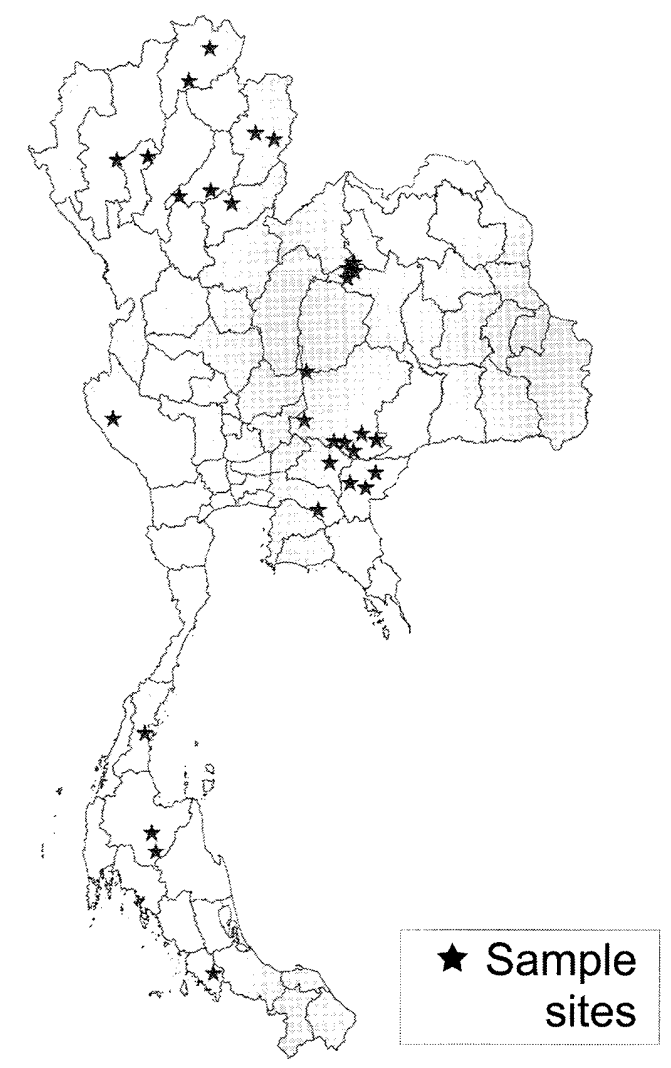

Fig. 1 Map showing sample sites for data collection
About ten forest village members of each project, who know very well about the village, were selected for an interview. The selection of interviewees was made by considering both gender and economic status. In comparison, the interview survey was also carried out with the farmers living in villages surrounding the forest reserved area. A correlation analysis was done to understand the relationship between land use patterns, landholding size, and basic needs of the farmers in each region of the country.

\section{RESULTS}

Agricultural Land Uses

In terms of cultivation area for field crops (Table 1), there was only a little difference among three categories of landholding sizes; small ( 0 - 15 rai : rai is a unit of land area, $6.25 \mathrm{rai}=1$ hectare), medium (16 -50 rai) and large (over 50 rai), indicating that farmers mostly think of growing crops as a first choice regardless how large the land they are cultivating. There are several reasons to support their decisions: 1) they have limited funds to invest, 2) they prefer to grow what they can consume with their family, 3) and the market is locally available for them to sell the crops.

Cultivation area of each agricultural land use varies by landholding size (Fig. 2). As a result of an interview survey, it seemed that there was no farmers holding large plots of land in the North, which can be attributed to hilly and mountainous characteristics of the region. Farmers with a small piece of land tended to make use of their land; mostly for field crops (38.5\% of total agricultural area). But farmers holding a medium sized plot of land would rather grow field crops (83.6\% of the area) than other agricultural land uses (Table 1).

Like in the northern region, major agricultural land use in the Northeast was field crop cultivation, which was (ranging from $60 \%-67 \%$ of the total agricultural area) among three groups of landholding plot size. Moreover, small landholding farmers seemed to grow a smaller area of paddy rice (only

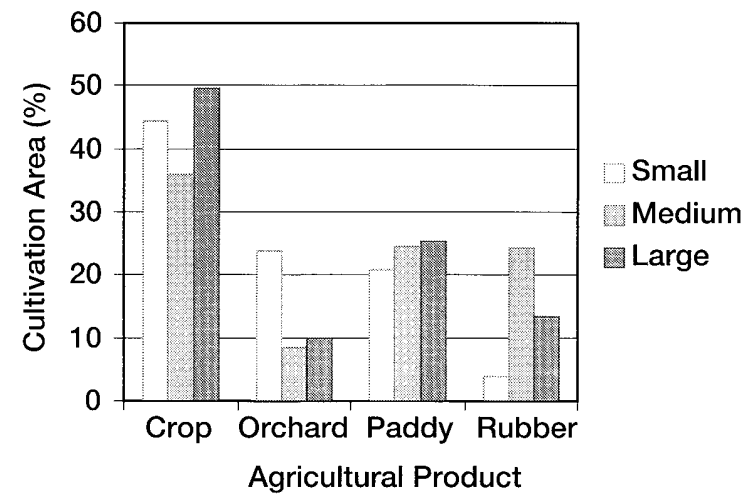

Fig. 2 Cultivation area by agricultural products and landholding size in nationwide 
Table 1 Cultivation area (\%) by agricultural land use and landholding size

\begin{tabular}{ccccccc}
\hline Land Holding Size & Region & Crop & Orchard & Paddy & Rubber & Other \\
\hline \multirow{4}{*}{$\begin{array}{c}\text { Small } \\
\text { (0-15 rai) }\end{array}$} & North & 38.5 & 30.3 & 23.5 & - & 7.7 \\
\cline { 2 - 7 } & Northeast & 67.0 & 18.8 & 11.8 & - & 2.4 \\
\cline { 2 - 7 } & Central & 33.0 & 12.5 & 38.5 & 4.9 & 11.1 \\
\cline { 2 - 7 } & South & 28.0 & 34.1 & 10.6 & 15.7 & 11.6 \\
\cline { 2 - 7 } & Nationwide & 44.3 & 23.7 & 20.8 & 3.7 & 7.5 \\
\hline \multirow{4}{*}{$\begin{array}{c}\text { Medium } \\
\text { (16-50 rai) }\end{array}$} & North & 83.6 & 8.2 & 8.2 & - & - \\
\cline { 2 - 6 } & Northeast & 60.2 & 13.3 & 21.7 & - & 4.8 \\
\cline { 2 - 6 } & Central & 14.9 & 10.5 & 48.3 & 13.9 & 12.4 \\
\cline { 2 - 6 } & South & 11.5 & 1.9 & 13.9 & 66.4 & 6.3 \\
\cline { 2 - 6 } & Nationwide & 36.0 & 8.5 & 24.6 & 24.3 & 6.6 \\
\hline \multirow{3}{*}{$\begin{array}{c}\text { Large } \\
\text { (over 50 rai) }\end{array}$} & North & - & - & - & - & - \\
\cline { 2 - 6 } & Northeast & 64.6 & 15.3 & 20.1 & - & - \\
\cline { 2 - 6 } & Central & 35.0 & 9.9 & 43.3 & 7.1 & 4.7 \\
\cline { 2 - 6 } & South & 35.3 & - & - & 64.7 & - \\
\cline { 2 - 6 } & Nationwide & 49.5 & 9.9 & 25.3 & 13.4 & 1.9 \\
\hline
\end{tabular}

1 rai $=0.16$ hectare or 1 hectare $=6.25$ rai

$11.8 \%)$ than those holding a larger piece of land.

Agricultural land use in the Central region was different from the two regions mentioned before. It was clear to see that the main agricultural land use was paddy rice, which was observed in all three groups of landholding sizes. Also, it was found that the paddy rice cultivation area in each group of landholding size was not much different. This is due to the fact that the lowland and flat areas in the Central region are most suitable for paddy rice cultivation. It was interesting to observe that field crop cultivation area in large landholding groups (35\% of land area of the region) also covered as big area as its in the small landholding group ( $33 \%$ of land area of the region). There could be two reasons: 1) the lands belong to large landholding farmers are not in the lowland close to water resources, or 2) large landholding farmers not only grew paddy rice but also they separated some part of their land for field crop cultivation. Landholding size in the South mainly falls in small and medium groups while very few farmers hold larger plots than 50 rai of land. In small landholding size, orchards cover the largest portion of land use, followed by crops, rubber and paddy. However, in medium landholding size, rubber plantations cover the largest portion of land use type, followed by paddy, crops and orchards.

\section{Agricultural Production}

From the interview survey, the farmers grew various species of trees, cash crops and fruit orchards. An overall view; rice ( $22.99 \%$ of the farmers) followed by maize or corn (18.97\%) and cassava (14.06\%) were the main crops grown by the farmers in forest village projects. Most of them (68.08\%) made use of their lands for cash crop production, and only

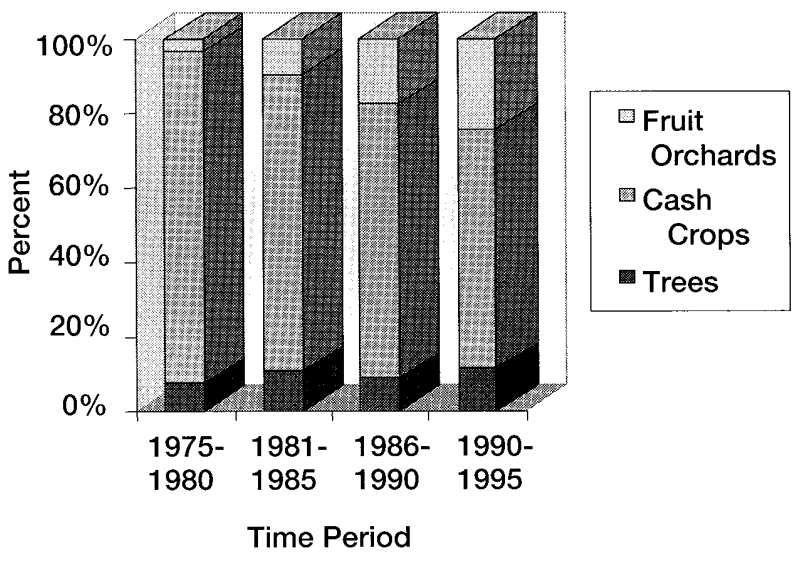

Fig. 3 Agricultural production by times in Nationwide

$22.54 \%$ for fruit orchards, and $9.38 \%$ for tree plantation.

By looking at the agricultural production in different periods of time from 1975 to 1995 , it was found that the farmers nationwide tended to decrease the production of cash crops, but increase the production of fruit orchards. In terms of tree planting, the farmers seemed to realize and pay more attention to the important role of forest tree plantation, especially fast growing tree species (Fig. 3).

Shifting cultivation have been widely practiced throughout the Northern region by both minority groups of hill tribes and lowland Thais. As a result of the interview survey, about $64 \%$ of the farmers grew cash crops, mainly rice (25.52\%), corn $(17.71 \%)$, and bean (10.94\%). Fruit mainly grown in this region were lychee, longan, and mango respectively. About $10 \%$ of forest cover was found in the Northeastern region. However, 
one-third of the country's population live in this region, most of them are relatively poorer than those in other regions. Agricultural productivity is also relatively low due to long dry seasons. Findings revealed that about $92.8 \%$ of the northeastern farmers grew cash crops, whereas $7.2 \%$ grew fruit orchards. Corn (36.8\%), cassava (35.2\%) and rice $(16.00 \%)$ were the main crops grown.

Geographically, areas in the Central region are characterized by flooded lowland. Therefore, about $80 \%$ of the farmers grow cash crops, followed by fruit orchards $(6.66 \%)$, and trees (5.33\%). The main crop production was rice, accounting for $42.67 \%$ of the farmers, followed by cassava $(25.33 \%)$ and corn $(8.00 \%)$. The general characteristics of Southern peninsula are rather different from the other regions. The central part of the South is covered by mountains, while areas in both eastern and western sides face the Gulf of Thailand and Andaman Sea respectively. The average annual rainfall is higher than 2,000 $\mathrm{mm}$., which is suitable for rubber plantation. The results from the interview survey indicated the fact that almost $70 \%$ of the farmers preferred to plant rubber trees for their main source of income.

Farmers' Socio-economic Conditions Migration

Migration or encroachment rate was increasingly high starting in 1965. People continued migrating into the forest illegally until 1975 when the Forest Village Project was started. However, the highest number of farmers that migrated into forest villages was in the period from 1980 to1985, because the farmers (at the beginning of the project) were still not sure and did not understand project implementation. The main reason for farmers to join the forest village project was that they needed more new land for farming (almost 50\% before the project started and almost $70 \%$ after the project started). The second main reason for joining the project was that they followed their families or relatives. About $10 \%$ of them joined the project because they could not cultivate their crop in their old land (due to drought, flooding, etc.). It could be observed that the number of farmers migrating into the project tended to decrease after 1985. This could be attributed to the following three reasons: 1) farmers may migrate to work in the industrial sector, 2) the project may have limited land provided to the farmers, and 3) other land allocation programs have been started such as Land Usufructuary Program (also known as Sor Tor Kor program), and the Land Reform Program. For those who were satisfied with the land and all the facilities provided by the project, they did not move out and at the same time they persuaded outsiders such as their friends and relatives to come and join the project. But those who were not satisfied left the village and returned to their old farms or looked for new land, or they may have kept their houses, but rented their farmlands to others and looked for other non-farm jobs outside the village.
In summary, based on the questionnaire survey, it could be noticed in every region that the farmers moved in and out gradually after the project started resulting in uncertain numbers of the population. Since 1982, the population did not change until 1994 when the government stopped providing support to the forest village projects except maintaining the forest plantations. Many of the farmers were unemployed by the project and were looking for sources of additional income.

\section{Source of Income}

Generally, the farmers earned their main income from two sources; sale of goods and as laborers, varying from region to region. Since the farmers usually have not enough income from their on-farm activities, many of them have other sources of income from off-farm activities. It could be, however, noticed that $42 \%$ of the farmers' main source of income was laborers wages, whereas $32 \%$ come from selling their goods and products (Fig. 4). By comparing the regions, the main sources of income in the Northern, Northeast, and Central regions were similar; laborers wages followed by the sale of goods. This could be explained that the income from agricultural production was not enough to support their living conditions. This might result from the following two reasons:

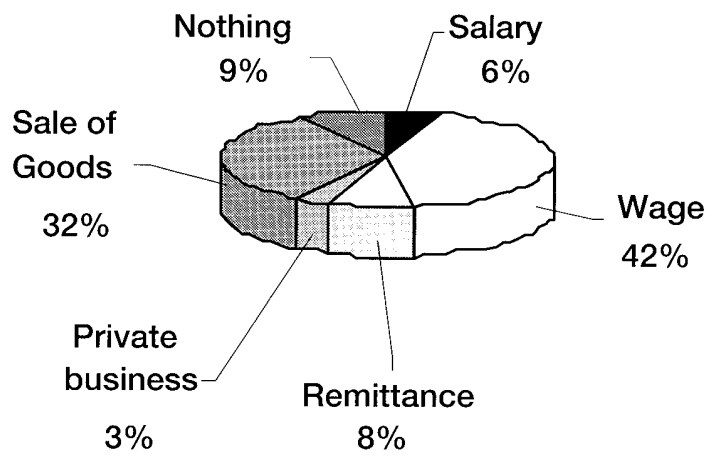

Fig. 4 Sources of income by number of villagers nationwide

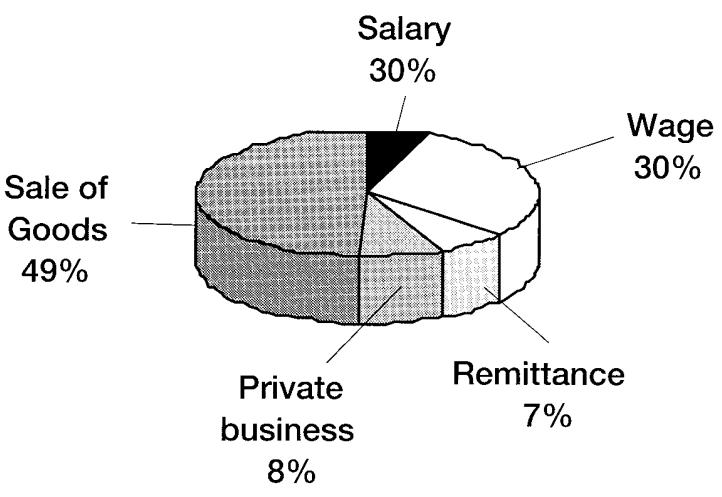

Fig. 5 Sources of income by the amount of income nationwide 
1) the land fertility was poor or the size of land was too small resulting in low productivity, 2) and there was not enough labor in the family. Therefore, the farmers worked as a laborer for their main source of income which required no cash investment.

Unlike other regions, the main source of income in the South was from the sale of goods, followed by laborers wages. This could be attributed to the living standard and socioeconomic condition of people in the South which is better than those in other regions. Income gained from the rubber tree plantations was very much higher than that gained from the same size of land cultivated with corn or cassava in the Northeastern region. Even though the price of rubber varies by the world market price, it is supported by the government when the price is lower than it should be.

Even though most of the farmers worked as a laborer for their main source of income, the amount of income earned from this wage was less than that earned from the sale of goods (Fig. 5). This could reflect the fact that the farmers work mainly on their farms and worked as a laborer on a part time basis, usually in the summer season. In many cases, the husband may, sometimes, go to work as a laborer inside or outside the village while the wife and, if available, their adult children take care of their farms. It was, therefore, meant that laborers wage was a second source of income.

Looking at different regions, it was found in the Northern, Northeastern, and Southern regions that the amount of income from the sale of goods was higher than that from a laborers wage. But the amount of income in the Central region was mainly generated from the laborers wages. This could be attributed to the fact that farmers were living in and near an industrial center which required more laborers. Farmers had better access to employment opportunities to generate income by working in factories.

Farmers' Needs Assessment

The main purpose of the Forest Village Project is to slow down the rate of deforestation caused by the people living in the forest areas. The project's principle is to move those people out from watershed and other protected areas, and settle them down in degraded forest areas suitable for agriculture. According to the interview survey, it was found that $85 \%$ of the interviewees were satisfied to continue living in the village. Only $6 \%$ of them expressed that they were not satisfied, the main reason was that they needed more land.

Although most of the farmers could meet their needs, it did not mean that they did not need more assistance and development from the government. The standard of living was relatively low compared to the villages outside the forests. Basic needs (income, infrastructure, land, water, electricity, health, dwelling, food, and education) assessment was carried out based on 5 degrees of satisfaction ranging from "Very Satisfied" to "Not Satisfied". The results showed that most of the farmers were not satisfied with their income, lands, water supply, and infrastructure. This could reflect the fact that land and water were still their main problems and were the most important basic needs. Particularly, land demand was raised up as the first priority to be discussed among the farmers. Currently, there is no absolute solution or clear policy on forest land management. There is no doubt that forest resources has been continuously encroached upon.

In order to be able to understand the needs of the farmers, all of the interviewed households were questioned about their most important needs and how much they were satisfied with these needs (using 5 percentage scores: $1=100 \%$ satisfied, $2=75 \%$ satisfied, $3=50 \%$ satisfied, $4=25 \%$ satisfied, and $5=$ not satisfied). Items not answered were discarded. Some of the preferences were directly related to individual household requirements (income, land, water, house, food) while others were community oriented (infrastructure, electricity, health or medical services, and education). In order to assess their priorities of need, an index of priority was applied as discussed in Poudyal (1990). The needs identified by the respondents in order of importance were: income, water, land, infrastructure, housing, food, electricity, health, and education (Table 2).

Table 2 Farmers' basic needs assessment

\begin{tabular}{cccccccccc}
\hline \multirow{2}{*}{ Ranking score } & \multicolumn{10}{c}{ Basic needs } \\
\cline { 2 - 11 } & Income & Water & Land & Infra-structure & House & Food & Electricity & Health & Education \\
\hline 1 & 17 & 46 & 68 & 38 & 73 & 50 & 136 & 108 & 126 \\
\hline 2 & 36 & 51 & 47 & 69 & 78 & 103 & 44 & 77 & 81 \\
\hline 3 & 89 & 61 & 57 & 84 & 70 & 91 & 16 & 44 & 35 \\
\hline 4 & 76 & 42 & 42 & 65 & 44 & 36 & 15 & 40 & 35 \\
\hline 5 & 79 & 95 & 86 & 34 & 28 & 8 & 63 & 18 & 8 \\
\hline Total Correspondents & 297 & 295 & 300 & 290 & 293 & 288 & 274 & 287 & 285 \\
\hline Total score & 1055 & 974 & 931 & 858 & 755 & 713 & 647 & 644 & 573 \\
\hline Mean score & 3.6 & 3.3 & 3.1 & 3.0 & 2.6 & 2.5 & 2.4 & 2.2 & 2.0 \\
\hline Index of priority & 0.89 & 0.83 & 0.78 & 0.74 & 0.64 & 0.62 & 0.59 & 0.56 & 0.50 \\
\hline
\end{tabular}


It is not surprising that income is the most important need. This is due to the fact that most of the interviewed farmers have not enough income. Even though they have a small piece of land for farming, they would be satisfied if they could earn enough income either from the sale of produce they can make on those lands or from other sources of income. According to the interview survey, the average annual income (including all sources of income) of the farmers in degraded forest reserves was about $28,000-30,000$ Baht or US $\$ 700-750$ ( 1 US $\$=40$ Baht). In the meantime, about $60 \%$ of them had to get a loan from the Bank of Agriculture and Agricultural Cooperatives with an average of $10,000-30,000$ Baht/year (about $30 \%$ of them hold a loan of less than 10,000 Baht, and the rest hold a loan of more than 30,000 Baht).

Water, especially for farming, was one of the most important needs. Although there had been provisions for water wells in the settlements as well as large water reservoirs, there was a lack of water especially in the dry season. The problem of irrigation was found to be the most prominent. Since field crop cultivation was an important source of employment as well as household earnings, owing to the rainfed conditions of the area, it could not contribute efficiently to strengthen the household economy of the farmers. In addition to water for farming, in many cases, they also lacked water for drinking and household consumption.

Land, especially for cultivation was the third most important need. The farmers living in degraded forest reserves will be provided with degraded land they have occupied but not more than 2.4ha (or 15 rai). Even though most of the interviewed farmers had been allocated with land for farming, about $43 \%$ of the total number of satisfied farmers awarded land expressed their opinion that this need had not been met as the land owned or allocated was too small.

Transportation and telecommunication are becoming important living factors in the life of the farmers. Due to the fact that most forest villages are located in remote areas, the farmers have limited access to the main road connecting to the city. Therefore, transportation of agricultural products to the market is very difficult resulting in an increased cost of their produce. The project has a small budget to construct and maintain roads. Some roads can not be used all year round. In addition, as information technology is growing very fast, the farmers are now considering the importance of having telephone lines or satellite telecommunication set up in several remote areas.

Other basic needs were electricity, health and education. However, many farmers still need better and permanent housing facilities. It was also noticed that farmers have started to realize the lack of local food which could be previously collected around the villages.
Income and Landholding Size

As mentioned earlier, the average annual income of the farmers living in degraded forests was about 30,000 Baht. However, the results from the interview survey indicated that about $60 \%$ of the farmers had an income lower than the average amount (Fig. 6). Moreover, 33.4\% of those farmers have annual incomes lower than 10,000 Baht. On the other hand, there was only about $18 \%$ of them that could support their families without difficulty.

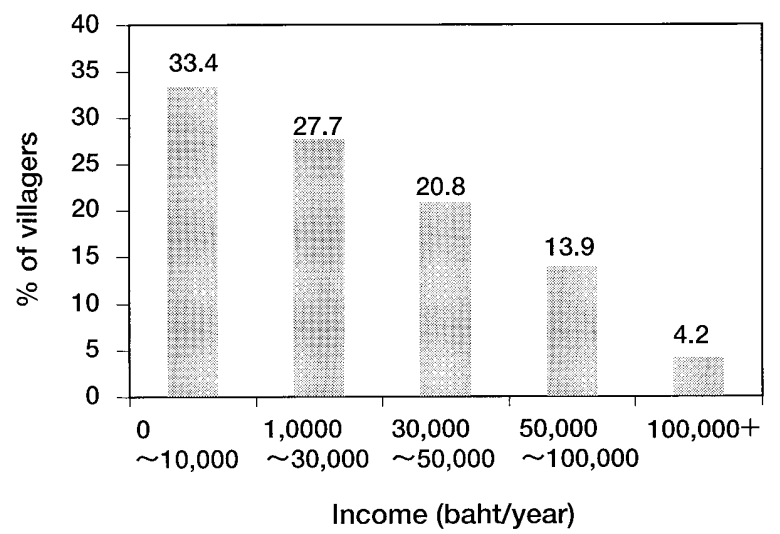

Fig. 6 Number of farmers by income
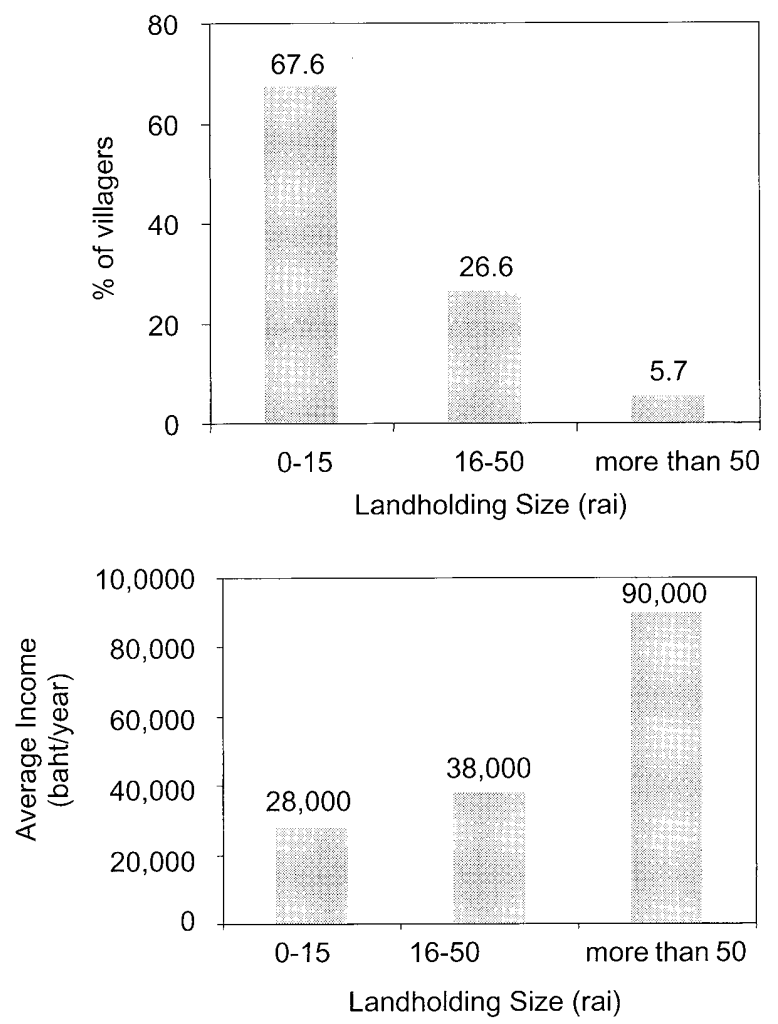

Fig. 7 Number of farmers and amount of income by landholding size 
Fig. 7 compared the number of farmers and amount of their income in relation to landholding size. It turned out that the number of farmers and amount of income were in the opposite direction in relation to landholding size. On the other hand, the number of farmers decreased, but the average income increased, as landholding size was bigger. This figure was not uncommon but indicated, to some extent, the existing problems of farmers' poverty with a small piece of farmland. And other related problems could be inevitably linked resulting in more complicated problems.

The results showed that the difference in average annual income of farmers by landholding size in each region of the country. By comparing the average annual income of the farmers in each region, farmers in the South earned the highest annual income ( 56,000 Baht), followed by those in the Central region (37,000 Baht), the Northeast (35,500 Baht) and the North $(24,500 \mathrm{Baht})$. In the same manner, it was a fact that farmers in the South earned more average annual income when looking at each landholding size.

But it was interesting to observe the difference among farmers in the medium-landholding group of the North, Northeast and Central regions. It was found that farmers in the North could gain higher annual income (66,500 Baht) than those in the Northeast (33,000 Baht) and the Central $(25,000$ Baht). There can be at least two factors to support this finding, 1) the difference in land uses; fruit trees may be the source of a higher income than cash crops, 2) and the additional source of income from off-farm activities.

Farmers' Need for Land and Landholding Size.

The answers of the farmers towards their needs for land were separated and compared based on the satisfaction ranking scores. Then the average landholding size of the farmers in each ranking score was also calculated. The figures in Table 3 showed the degree of farmers' need for land and their average landholding size. Due to the result from this study, we could only learn extensively the land demanding situation of the farmers at the time being. There were about $37.21 \%$ of the farmers who were satisfied with their landholding size (75\% satisfied and more), and about $46.51 \%$ of those who were not satisfied (25\% satisfied and less). Meanwhile, about $16.28 \%$ of the farmers were moderately satisfied (50\% satisfied). It is rather difficult to say how large exactly of landholding size the farmers would be satisfied as we need to concern with other factors, for example, farmers' potential (in terms of capital, labor, know-how, and so on); land use patterns; site conditions of the land. However, this findings were based on the calculation of overall data collected from the interview survey. The comparison of this relationship was not made in each region of the country, but tended to be not much different.
Table 3 Relationship between farmers' needs and landholding size

\begin{tabular}{ccc}
\hline Degree of needs & $\begin{array}{c}\text { Percent of } \\
\text { respondents }\end{array}$ & $\begin{array}{c}\text { Average landhold- } \\
\text { ing size (rai) }\end{array}$ \\
\hline 100\% satisfied (score 1) & 22.09 & 25.3 \\
\hline 75\% satisfied (score 2) & 15.12 & 14.7 \\
\hline 50\% satisfied (score 3) & 16.28 & 13.7 \\
\hline 25\% satisfied (score 4) & 14.73 & 10.5 \\
\hline Not satisfied (score 5) & 31.78 & 8.1 \\
\hline
\end{tabular}

Table 4 Relationship between farmers' need and gaining income

\begin{tabular}{cc}
\hline Degree of Needs & $\begin{array}{c}\text { Average annual income } \\
\text { (Baht) }\end{array}$ \\
\hline 100\% satisfied (score 1) & 45,500 \\
\hline $75 \%$ satisfied (score 2) & 43,500 \\
\hline $50 \%$ satisfied (score 3) & 40,000 \\
\hline 25\% satisfied (score 4) & 32,000 \\
\hline Not satisfied (score 5) & 30,000 \\
\hline
\end{tabular}

Farmers' Need for Income and Gaining Income

As was done in farmers' need for land, the calculation was separately made to compare the average income of farmers in each ranking score of their need for income. It could be implied from the results in Table 4 that the farmers would be $100 \%$ satisfied if they could earn more than 45,500 baht annually, or at least, they should be able to earn about 40,000 baht annually, which is higher than the average annual income of farmers who have medium size of landholding. The important points to be addressed here are: 1) whether or not farmers make use of their land efficiently, 2) what can be their additional sources of income, and whether or not the government can provide them with more land.

Table 4 Relationship between farmers' need for income and gaining income.

\section{DISCUSSIONS AND CONCLUSIONS}

The results from this study could reflect the farmers' behavior of how they spend their life in degraded forests, in terms of land utilization and agricultural production. In addition, their problems and basic needs could be identified as well in comparison of each region of the country. Lessons learned from this study can be of great benefits for the decision maker to find ways for the solution of farmers' problems and needs. For example, the farmers would be rather satisfied if they could earn more than 45,500 baht annually for their income, but their average annual income was about $28,000-30,000$ baht. It is meant that the government 
policy must emphasize on the promotion of off-farm employment for farmers' additional income in local areas in order to meet with their need. This would help improve farmers' living standard and they would no longer move farming lands and encroach more forest lands. Additionally, by doing this, farmers would not be necessary to migrate and work as a labor in the city. In the meantime, the government policy, however, must provide enough support (especially source of water for both consumption and farming) for their subsistence farming so that they could save their expenses of household consumption.

Land is also one of the most wanted needs by farmers in all regions, and is the most critical issue for policy makers due to its complication. Most of farmers living in degraded forests are holding small piece of land (not lager than 15 rai) and need more land for farming. Based on the results of this study, they would be very satisfied if they could be provided with larger piece of land (an average of 25 rai per household approximately). However, the suitable size of land to be allocated to the farmers is a controversial question because land in each region are different in terms of physical and biological conditions. Lacking of land for farming is still one of the major causes of deforestation which is difficult to be overcome by a specific land allocation policy. But helping the farmers improve the efficiency of land utilization process by introducing new suitable technologies could be a possible way to decrease the demand of land and consequently to slow down the degree of deforestation.

Infrastructure, like transportation and telecommunication, is also important and needed since farmers living remotely in degraded forests have less access to main road and communication medias. Agricultural products could not be easily transported to the local available markets resulting the higher cost or lesser income. Expanding local road network to the remote areas could be positive reason for social and economic development. But in the opposite manner, it could be negative or risky to the forest protection measurement as the forest encroacher could have more access to the forests. The establishment of local community cooperatives should be taken into consideration and promoted to help farmers, to some extent, solve their own problems.

Other problems and needs (house, health, electricity and education) seemed to be not serious issues for the farmers because they could be provided with some little difficulty.

\section{LITERATURE CITED}

Allen, J.C. and BarNES, D.F., (1985): The cause of deforestation in developing countries. Annals of the Association of American Geographers 75: 163-184

Bilsborrow, R. and Geores, M., (1994): Population, land-use and the environment in developing countries: What can we learn from cross sectional data?. In Brown, K. and PeArCE, D.W. (eds.) The cause of tropical deforestation. 106-133. UBC press, Vancouver

BuRgESS, J.C., (1991): Economic analysis of frontier agriculture expansion and tropical deforestation. M.Sc. Thesis. Environmental and Resource Economics, University College London, 94 pp.

Grainger, A., (1986): The future role of world tropical forest economy. Ph.D. Diss., Oxford University, 115 pp.

GREPPERUD, S., (1996): Population pressure and land degradation. Journal of Environmental Economics and Management 30:18-33

Palo, M., Salami, J. and Gerado, M., (1987): Deforestation in tropics: Pilot scenarios based on quantitative analysis. In MatnI, P.M. and Salami, J. (eds), Deforestation or development in the third world. 53-106. Finnish Forest Research Institute

Panayotou, T. and Sungsuwan, S., (1989): An econometric study of the cause of tropical deforestation: The case of northeast Thailand. Discussion Paper. Harvard Institute of International Development, Cambridge, 38 pp.

Poudyal, L., (1990): People's involvement in planned district development through decentralization in Nepal. (Ph.D. Dissertation), Bangkok: Institute for Social Science, Chulalongkorn University, $434 \mathrm{pp}$.

Reis, E.J. and Margulis, S., (1990): Economic perspectives on deforestation in the Brazilian Amazon. Paper presented at the Project Link Conference, Manila, Nov. 5-9

Royal Forest Department, (1986): Forestry statistics of Thailand. 1986, Bangkok, 74 pp. (In Thai)

Royal Forest Department, (1989): Forestry statistics of Thailand. 1989, Bangkok, 79 pp. (In Thai)

Royal Forest DePaRtMent, (1995): Forestry statistics of Thailand. 1995, Bangkok, 150 pp. (In Thai)

Royal Forest Department; (1999): Forestry statistics of Thailand. 1999, Bangkok , 153 pp. (In Thai)

Southgate, D., (1994): Tropical deforestation and agriculture development in Latin America. In Brown, K. and Pearce, D.W. (eds.) The cause of tropical deforestation. 134-145. UBC press, Vancouver

Westoby, J.C., (1978): Forest industry for socio-economic development. Commonwealth Forestry Review 58:107-116

(Received 16 October 2005) (Accepted 18 April 2006) 